\title{
Isolation Improvement of a Microstrip Patch Array Antenna for WCDMA Indoor Repeater Applications
}

\author{
Hongmin Lee and Jinwon Park \\ Department of Electronic Engineering, Kyonggi University, Suwon 443-760, Republic of Korea \\ Correspondence should be addressed to Hongmin Lee, hmlee@kyonggi.ac.kr
}

Received 15 July 2011; Revised 5 November 2011; Accepted 17 November 2011

Academic Editor: Byungje Lee

Copyright (C) 2012 H. Lee and J. Park. This is an open access article distributed under the Creative Commons Attribution License, which permits unrestricted use, distribution, and reproduction in any medium, provided the original work is properly cited.

This paper presents the isolation improvement techniques of a microstrip patch array antenna for the indoor wideband code division multiple access (WCDMA) repeater applications. One approach is to construct the single-feed switchable feed network structure with an MS/NRI coupled-line coupler in order to reduce the mutual coupling level between antennas. Another approach is to insert the soft surface unit cells near the edges of the microstrip patch elements in order to reduce backward radiation waves. In order to further improve the isolation level, the server antenna and donor antenna are installedin orthogonal direction. The fabricated antenna exhibits a gain over $7 \mathrm{dBi}$ and higher isolation level between server and donor antennas below $-70 \mathrm{~dB}$ at WCDMA band.

\section{Introduction}

Microstrip patch antennas are used in modern communication systems due to their low cost, lightweight, and planar structure. However, a microstrip patch antenna has some disadvantages.

In the design of a microstrip patch array antenna, the radiating patch elements have to be placed in close proximity. It produces significant mutual coupling effect that deteriorates the antenna performance. The simplest solution to improve the antenna isolation is to increase the physical separation between the antennas. Although the isolation of the antennas becomes higher as the separation length is increased, the size of the antenna will subsequently be larger. However, the size of the antenna ground plane is limited in the practical microstrip patch antenna design. Particularly when the patch antenna is printed on high dielectric substrates, its radiation pattern is considerably affected by surface waves. On a finite ground plane, surface waves propagate until they reach an edge where they are reflected back and diffracted by the edges. These cause a significant amount of wasted power in the backward hemisphere below the ground plane. Various solutions for the improvement of the radiation performance of patch antennas on a substrate are available. One approach is to construct a periodic structure, such as photonic bandgap (PBG) or electromagnetic bandgap (EBG) $[1,2]$, surrounding the patch antenna. Another approach is to use the concept of artificial soft and hard surfaces [3]. These surfaces have led to a wide range of applications in antennas other microwave systems [4]. Both EBG and soft surfaces can be used to suppress surface wave propagation. The main difference is that soft surfaces exhibit bandgaps in only one direction, but they offer the best performance in most applications of antennas. However, the conventional soft surfaces are made on the same ground plane of a patch antenna and the presence of via near the patch may raise the resonant frequency of the patch if the soft surface strip or cell is very close to the patch. On the other hand, it requires a considerable area to form a bandgap structure.

The purpose of this paper is to present a new method for enhancing an isolation of a microstrip patch array antenna, whose $\mathrm{Tx} / \mathrm{Rx}$ band is located very near. In order to reduce the mutual coupling between antennas that are located in the same plane, a passive switching feed network is used [5]. A new isolated soft surfaces structure that does not share the ground plane of a patch is also used for the reduction of the surface wave. The proposed new soft surface consists of a 
number of metal mushroom-type structures that is located near the edges of substrate, and it is not connected with a ground plane $[6,7]$. A two-by-two microstrip patch array antenna for the indoor wideband code division multiple access (WCDMA) repeater applications is designed and tested experimentally.

\section{Switchable Feed Network for Antenna}

The schematic of a single-feed switchable feed network is shown in Figure 1. It basically consists of two quarterwavelength branch lines with characteristic impedances of $Z_{1}$ and $Z_{2}$ lengths of $l_{1}$ and $l_{2}$. Two different rectangular microstrip patch antennas of different sizes are connected to output ports 2 and 3 . The resonant frequencies of these two antennas are $f_{1}$ and $f_{2}$, and the input impedances of each antenna are $Z_{L 1}$ and $Z_{L 2}$. Lengths of $l_{1}$ and $l_{2}$ are chosen as a quarter wavelength of $\lambda_{1} / 4$ and $\lambda_{2} / 4$, respectively. When a signal with a frequency of $f=f_{1}$ is applied to port 1 , the input impedance of the upper branch $Z_{\text {in } 1}$ is

$$
Z_{\text {in } 1}=\frac{Z_{1}^{2}}{Z_{L 1}} .
$$

If the resonant frequencies of two patches are very closely located $\left(f_{1} \approx f_{2}\right)$, the two quarter wavelength branch line lengths become similar $\left(l_{1} \approx l_{2}\right)$. Since the patch antenna connected to port 3 is off-resonant, the input impedance of the antenna is almost reactive $\left(Z_{L 2} \approx j X\right)$. Hence, the input impedance of the lower branch $Z_{\text {in }}$ is

$$
Z_{\text {in } 2}=Z_{2} \frac{Z_{L 2}+j Z_{2} \tan \beta_{2} l_{2}}{Z_{2}+j Z_{L 2} \tan \beta_{2} l_{2}} \approx-j \frac{Z_{2}^{2}}{x} .
$$

When the patch antenna was off-resonant, its input reactance neared zero $(x \rightarrow 0)$. Using $x \rightarrow 0$ in (2), the input impedance of port 2 neared infinity $\left(Z_{\text {in2 }} \rightarrow \infty\right)$. Therefore, it acts as an open circuit. As a result, the patch at port 2 would be at resonance with the patch at the off-resonant port 3. If a signal with a frequency of $f=f_{2}$ is applied to port 1 , the patch at port 3 will be at resonance with the off-resonant patch at port 2 . This single-feed switchable feed network combines two ports of a microstrip antenna with a quarter wavelength feed line and each resonant frequency of the antennas very closely located; it acts as an ideal single-pole double-throw (SPDT) switch. The operation of the single-feed switchable feed network when $Z_{1}=$ $Z_{2}=Z_{L 1}=Z_{L 2}=50 \mathrm{ohm}$ is presented in Table 1. In order to further enhance the isolation between the ports, microstrip/negative-refractive-index (MS/NRI) coupled line coupler is used with the switchable feed network. An MS/NRI coupler has advantages, compared to conventional edgecoupled microstrip couplers in terms of coupled power and port isolation [8]. Figure 2 shows the geometry of the $3 \mathrm{~dB}$ MS/NRI coupled-line coupler for WCDMA frequency band $(1.92-2.17 \mathrm{GHz})$ applications. It consists of a conventional MS right-handed transmission line edge-coupled with a NRI transmission line used in its left-handed range. A $3 \mathrm{~dB}$ implementation of the MS/NRI coupled-line coupler requires the equality of the magnitude at port 2 and port

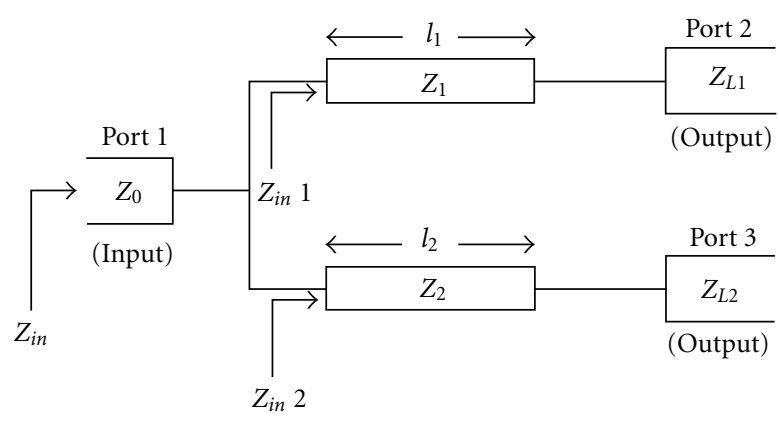

Figure 1: Schematic of a single-feed switchable feed network.

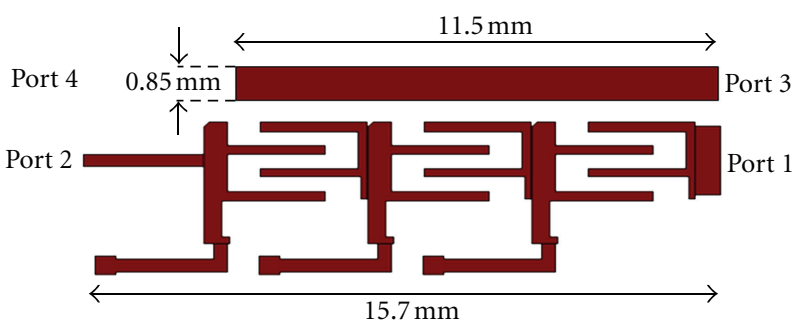

FIgURE 2: Geometry of $3 \mathrm{~dB}$ MS/NRI coupled-line coupler.

TABLE 1: The operation of the single-feed switchable feed network.

\begin{tabular}{lcccc}
\hline$f[\mathrm{GHz}]$ & Port & $Z_{\text {in }}$ & $Z_{L}$ & Switch state \\
\hline \multirow{2}{*}{$f=f_{1}$} & Port 2 & $50 \Omega$ & $50 \Omega$ & "On" \\
& Port 3 & $\approx \infty \Omega$ & $j x \approx 0 \Omega$ & "Off" \\
\multirow{2}{*}{$f=f_{2}$} & Port 2 & $\approx \infty \Omega$ & $j x \approx 0 \Omega$ & "Off" \\
& Port 3 & $50 \Omega$ & $50 \Omega$ & "On" \\
\hline
\end{tabular}

$3\left(\left|S_{21}\right|=\left|S_{31}\right|\right)$. Usually the total length of the coupler and the spacing between the lines should be adjusted until a $3 \mathrm{~dB}$ coupling level is acquired. A $3 \mathrm{~dB}$ MS/NRI coupled-line coupler is designed on a Rogers RO3210 substrate (relative dielectric constant $=10.2$, thickness $=2.54 \mathrm{~mm}$ ).

The NRI transmission line was $15.7 \mathrm{~mm}$ long and the MS-line was $11.5 \mathrm{~mm}$ long. The spacing between MS/NRI lines is $1 \mathrm{~mm}$. Figure 3 presents the simulated scattering parameter results for the MS/NRI coupled-line coupler of Figure 2. Quasi-3 dB backward coupling is achieved over the range from 1.7 to $2.7 \mathrm{GHz}$. The magnitudes of the simulated $S$-parameter are listed in Table 2. Figure 4 shows the geometry of the feed network for two-by-two microstrip patch array antenna. It is fed by a $50 \Omega$ coaxial probe and designed on a Rogers RO3210 substrate to allow the feeding of a four-element microstrip patch antenna array. The overall dimension of the ground plane is $120 \mathrm{~mm} \times 120 \mathrm{~mm}$. The aimed two switching frequencies of the proposed switchable feed network are 1.95 and $2.14 \mathrm{GHz}$, respectively.

These frequencies are the center of the Tx and $\mathrm{Rx}$ band in the WCDMA system. In Figure 4, all the ends of each port of the proposed feed network for two-by-two microstrip patch antenna are made with $50 \Omega$ microstrip lines. The characteristic impedances of an NRI transmission line and the MS line were $Z_{1}=90 \Omega$ and $Z_{2}=75 \Omega$, respectively. 


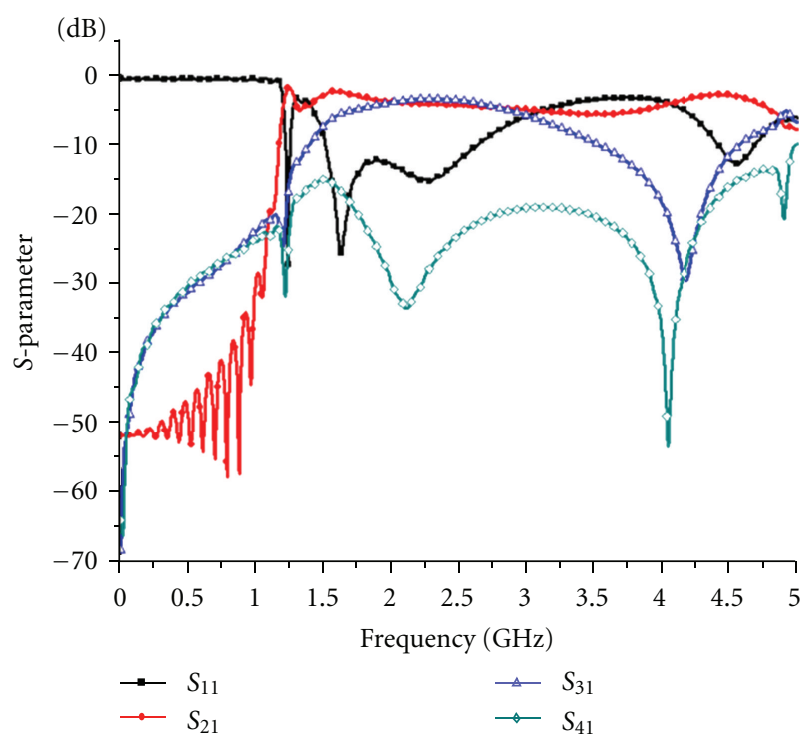

FIGURE 3: Simulated $S$-parameter results for the MS/NRI coupledline coupler of Figure 2.

TABle 2: Simulated S-parameters for the MS/NRI coupled-line coupler.

\begin{tabular}{lcc}
\hline$S$-parameter & $1.95 \mathrm{GHz}[\mathrm{dB}]$ & $2.14 \mathrm{GHz}[\mathrm{dB}]$ \\
\hline$S_{11}$ & -12.5 & -13.4 \\
$S_{21}$ & -3.3 & -3.6 \\
$S_{31}$ & -3.6 & -3.1 \\
$S_{41}$ & -27.5 & -32.5 \\
\hline
\end{tabular}

TABle 3: Simulated S-parameters of the feed network for a fourelement microstrip patch array.

\begin{tabular}{|c|c|c|c|c|}
\hline Frequency & \multicolumn{2}{|c|}{1.94} & \multicolumn{2}{|c|}{2.15} \\
\hline \multicolumn{5}{|c|}{ Port isolation $[\mathrm{dB}]$} \\
\hline$S$-parameter & $\begin{array}{c}\text { Without } \\
\text { MS/NRI } \\
\text { coupler }\end{array}$ & $\begin{array}{c}\text { With } \\
\text { MS/NRI } \\
\text { coupler }\end{array}$ & $\begin{array}{c}\text { Without } \\
\text { MS/NRI } \\
\text { coupler }\end{array}$ & $\begin{array}{c}\text { With } \\
\text { MS/NRI } \\
\text { coupler }\end{array}$ \\
\hline$S_{23}$ & -15.18 & -18.81 & -11.18 & -18.78 \\
\hline$S_{24}$ & -14.66 & -24.73 & -12.20 & -17.12 \\
\hline$S_{25}$ & -7.03 & -23.25 & -7.8 & -19.57 \\
\hline$S_{32}$ & -15.18 & -19.81 & -11.18 & -23.09 \\
\hline$S_{34}$ & -8.50 & -24.01 & -8.04 & -30.99 \\
\hline$S_{35}$ & -16.88 & -26.69 & -10.43 & -18.91 \\
\hline$S_{42}$ & -14.66 & -24.73 & -12.20 & -17.10 \\
\hline$S_{43}$ & -8.50 & -24.01 & -8.04 & -30.99 \\
\hline$S_{45}$ & -16.31 & -18.26 & -11.67 & -20.54 \\
\hline$S_{52}$ & -7.03 & -23.25 & -7.8 & -19.57 \\
\hline$S_{53}$ & -16.88 & -26.69 & -10.43 & -18.92 \\
\hline$S_{54}$ & -16.04 & -18.26 & -11.67 & -20.54 \\
\hline
\end{tabular}

In order to match these impedances with $50 \Omega$ port, a single section of quarter wavelength impedance transformer was added. The proposed feed network was designed by using

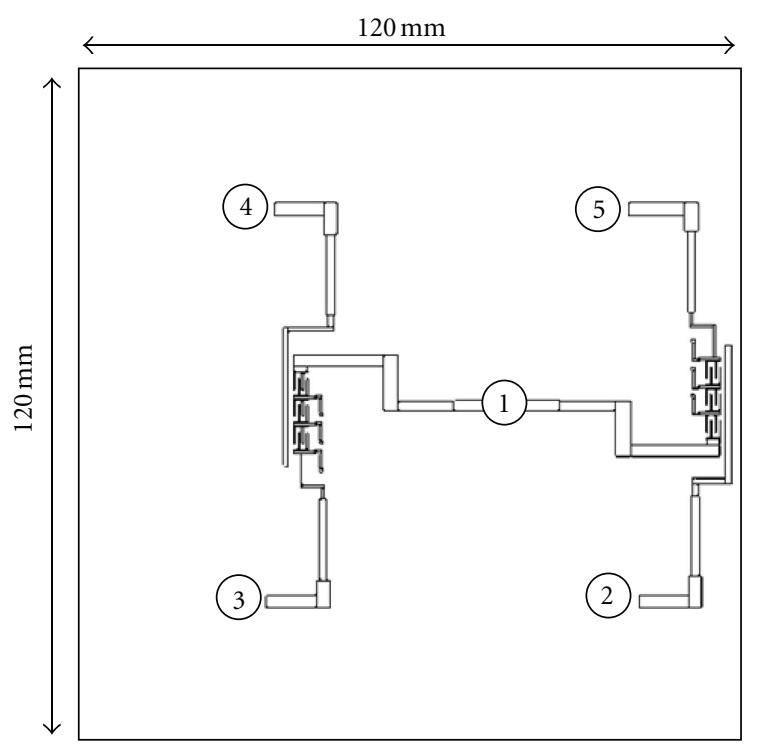

FIGURE 4: Geometry of the feed network for two-by-two microstrip patch array antenna.

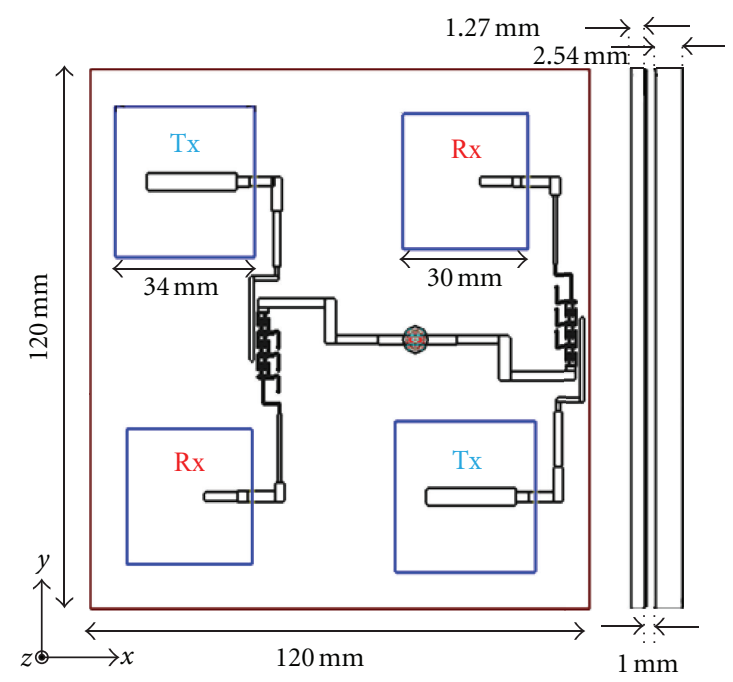

Figure 5: Geometry of the proposed switchable feed network for two-by-two microstrip patch array antenna.

switched feeder network and a signal was excited at port 1 as shown in Figure 4. When the antennas connected at port 2 and port 4 were in an on state, the antennas connected at port 3 and port 5 were in an off state. However, the proposed switchable feed network shown in Figure 1 can operate when the antennas are connected at each port.

For the simulation of the port isolation, all the ends of each port were terminated with microstrip patch antennas. The simulated scattering parameters of the proposed switchable feed network compared to those of the switchable feed network with/without MS/NRI coupled-line coupler are listed in Table 3. The switchable feed network with MS/NRI coupled-line coupler exhibits much higher isolation than the switchable feed network without MS/NRI coupled-line 


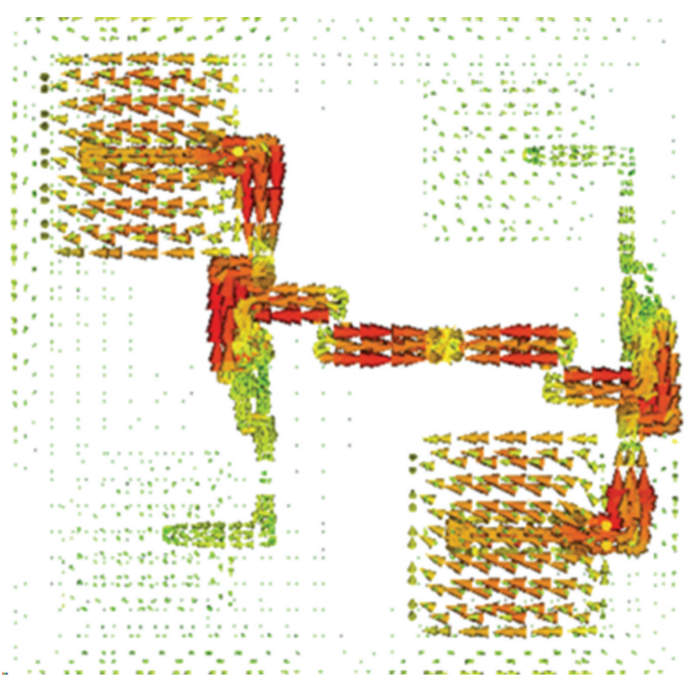

(a) $1.95 \mathrm{GHz}$

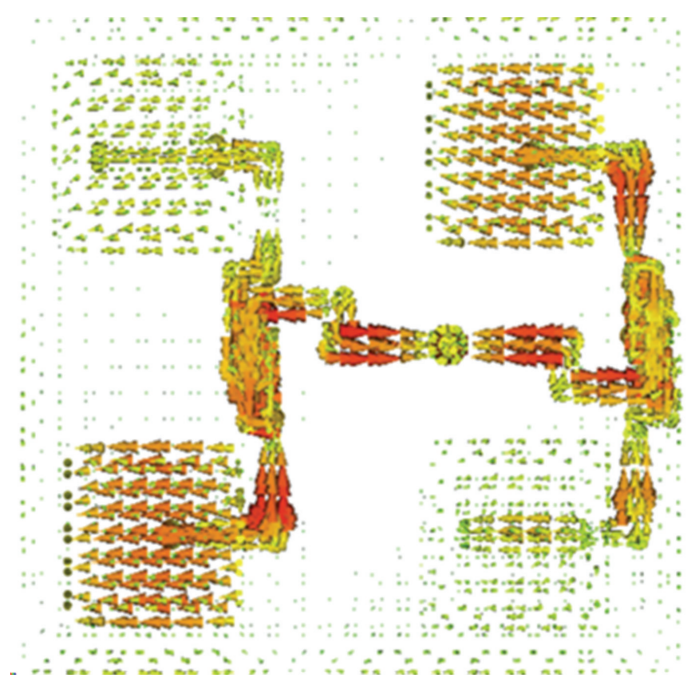

(b) $2.15 \mathrm{GHz}$

FIGURE 6: Simulated surface current distributions.

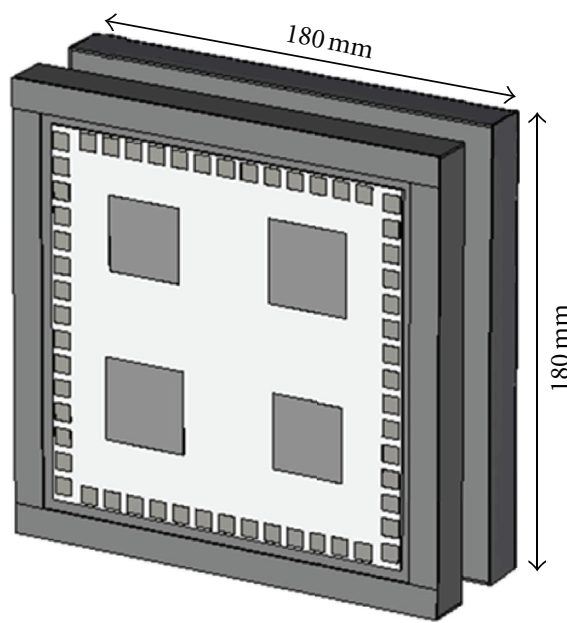

(a) Perspective view

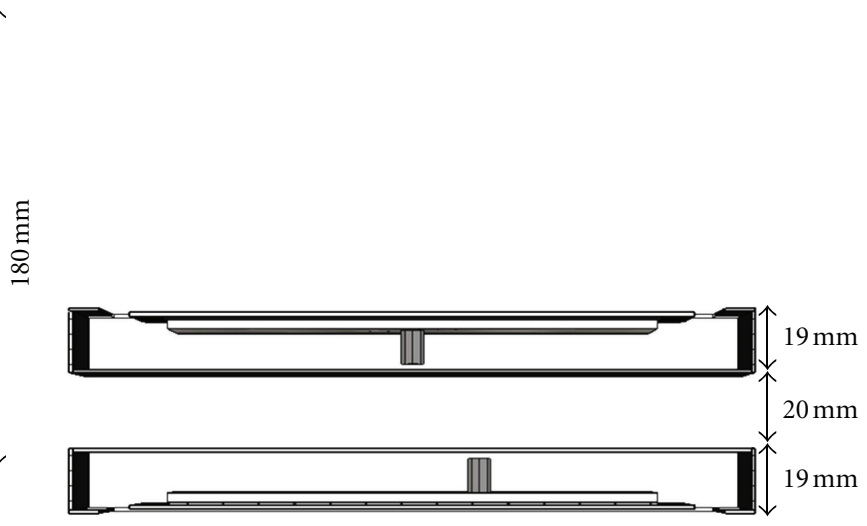

(b) Side view

FIGURE 7: Geometry of the proposed indoor WCDMA repeater antenna.

coupler. When the MS/NRI coupled-line coupler was not used, the scattering parameters $\left(S_{25}, S_{34}, S_{52}, S_{43}\right)$ between two antennas showed lower isolation. Since the patch antennas were designed to be excited at their fundamental resonant mode $\left(\mathrm{TM}_{10}\right)$, strong coupling is produced between two antennas that are placed parallel to the radiating edge direction. It can be seen that the minimum isolation levels between the output ports exceed $-18 \mathrm{~dB}$ at the aimed two switching frequencies of the proposed switchable feed network.

\section{Antenna Design}

Figure 5 shows the geometry of the two-by-two microstrip patch array antenna using the proposed switchable feed network and proximity coupled square microstrip patch elements.
The antenna consists of three-layer structure: an air layer having a thickness of $1 \mathrm{~mm}$, a dielectric substrate layer, and a stacked microstrip patch layer. The square microstrip patches are fed by microstrip lines from perpendicular directions using the proximity coupled method. This switchable feed network was designed to achieve beam pattern reconfigurable array antenna, which generates $\pm 45^{\circ}$ linearly polarized slanted beam patterns at the $\mathrm{Tx} / \mathrm{Rx}$ frequency bands. In order to dual slant beam, two Rx and Tx microstrip patch elements were placed orthogonally. Figure 6 shows the simulated surface current distribution at the resonant frequency of $1.95 \mathrm{GHz}(\mathrm{Tx})$ and $2.15 \mathrm{GHz}(\mathrm{Rx})$. At the frequency of $1.95 \mathrm{GHz}$, two patch antennas for $\mathrm{Tx}$ band are resonant, and two patch antennas for $\mathrm{Rx}$-band are offresonant. As a result, most of the surface currents flow through the feed line for Tx-band antennas. On the other hand, at the frequency of $2.15 \mathrm{GHz}$, two patch antennas for 


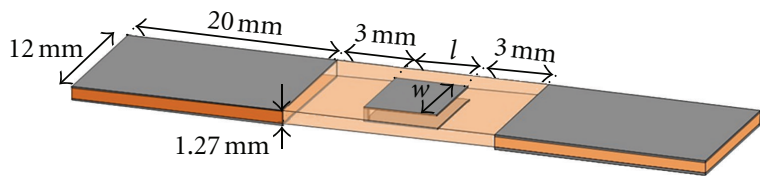

(a) Parallel plate waveguide model with a cell

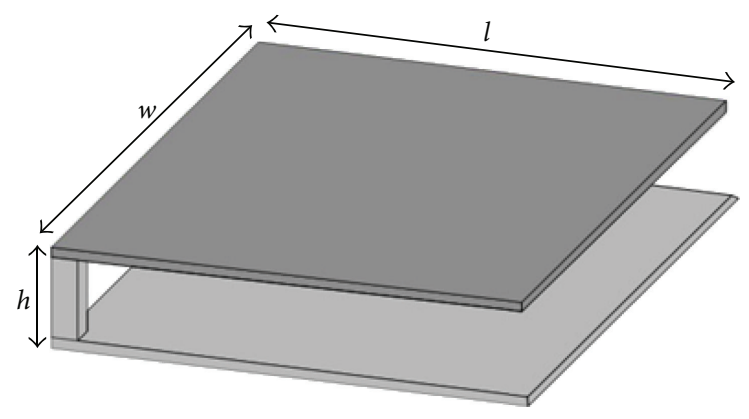

(b) Geometry of unit cell

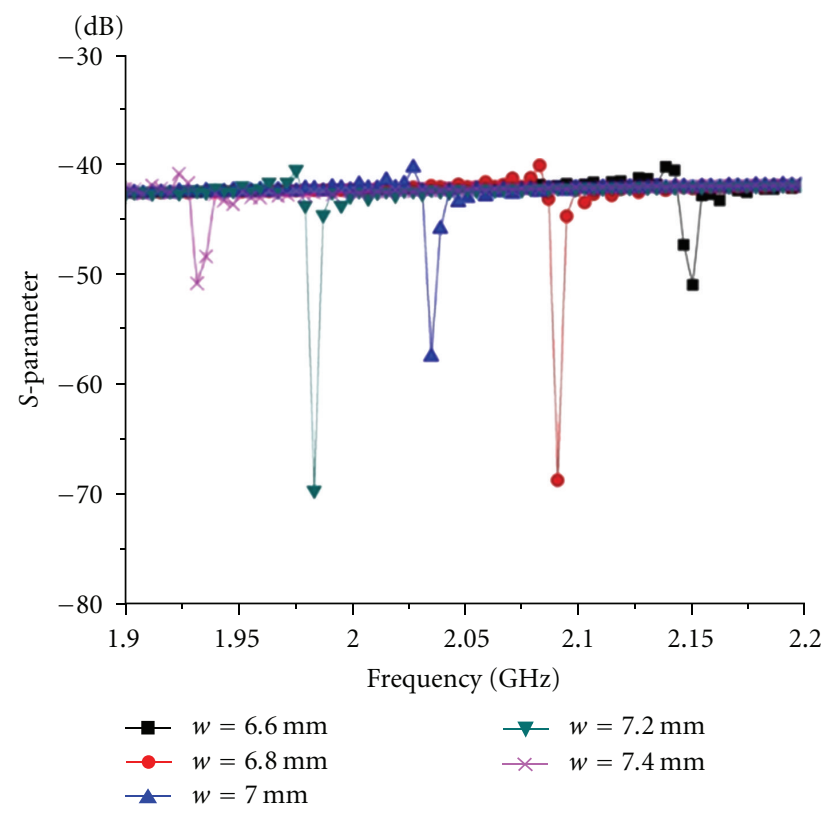

(c) The simulated transmission characteristics with different sizes of unit cells

FIGURE 8: Parallel plate waveguide model with different sizes of unit cells.

$\mathrm{Rx}$ band are resonant. The perspective view of a microstrip patch array antenna system for the indoor WCDMA repeater is shown in Figure 7. The proposed repeater antenna consists of a server antenna, a donor antenna, and alumina housing. It occupies a volume of $180 \mathrm{~mm} \times 180 \mathrm{~mm} \times 20 \mathrm{~mm}$. In order to reduce the surface waves radiation from a server antenna and a donor antenna, corner-edged via mushroom-type unit cells are formed near the edges of the upper dielectric substrate. Figure 8 shows the parallel plate waveguide model with different sizes of unit cells and the results of the simulated transmission characteristics as a function of frequency. As shown in Figure 8(b), the unit cell consists of two parallel rectangular plates with the same size $(w=l)$ and a corner-edged via. The height of the via is $1.27 \mathrm{~mm}$. Inside two rectangular plates, dielectric material (relative dielectric constant $=10.2$, thickness $=1.27 \mathrm{~mm})$ is placed. The transmission coefficient $S_{21}$ of the parallel plate waveguide ports without cell exhibits near $-43 \mathrm{~dB}$, as shown in Figure 8(c). When the unit cell is inserted between two parallel plate waveguides, a stop band occurs at a certain frequency.
It depends on the physical size of the unit cell However, the bandwidth of each stop band shows very narrow characteristics due to the resonant nature of the unit cell and a high dielectric constant of the substrate. In order to cover the bandwidth within the WCDMA frequency band, three different sizes of unit cell array configuration structure $(w=l=6.6 \mathrm{~mm}, 7.0 \mathrm{~mm}, 7.4 \mathrm{~mm}$ ) were used in this work. In addition, a server antenna and a donor antenna backed by the alumina housings are arranged in orthogonal direction in order to get higher isolation between two antennas.

\section{Experimental Result}

The photographs of the fabricated two-by-two microstrip patch array antenna structure are shown in Figure 9. The switchable feeder layer and a stacked microstrip patch layer are etched on a Rogers RO3210 substrate (relative dielectric constant $=10.2$ ) having different thickness of $2.54 \mathrm{~mm}$ and $1.27 \mathrm{~mm}$, respectively. The characteristic impedance of each of the two branch feed lines from the coaxial 


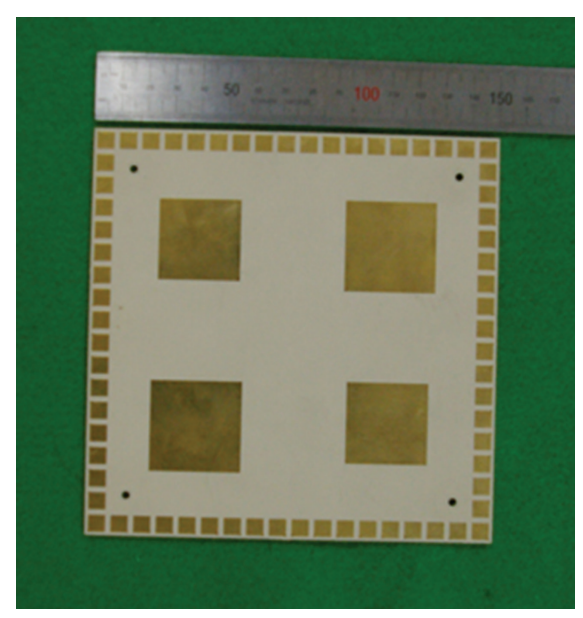

(a) Top view

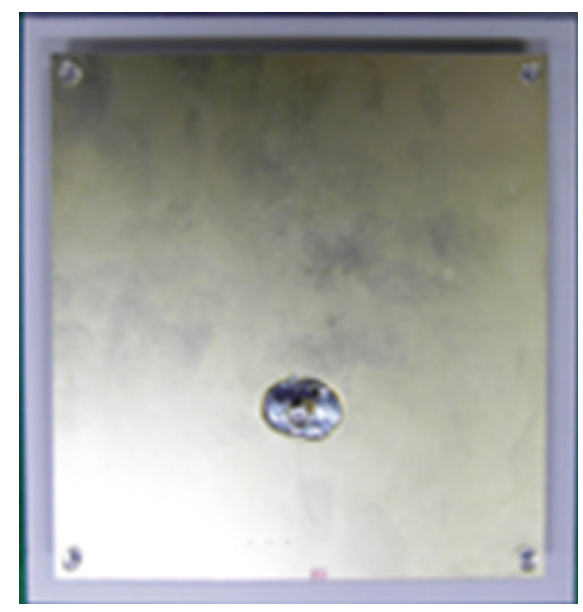

(c) Ground plane

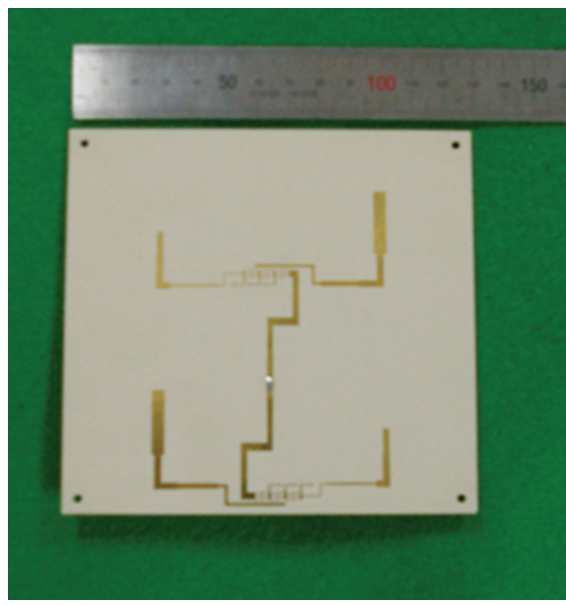

(b) Switchable feed network

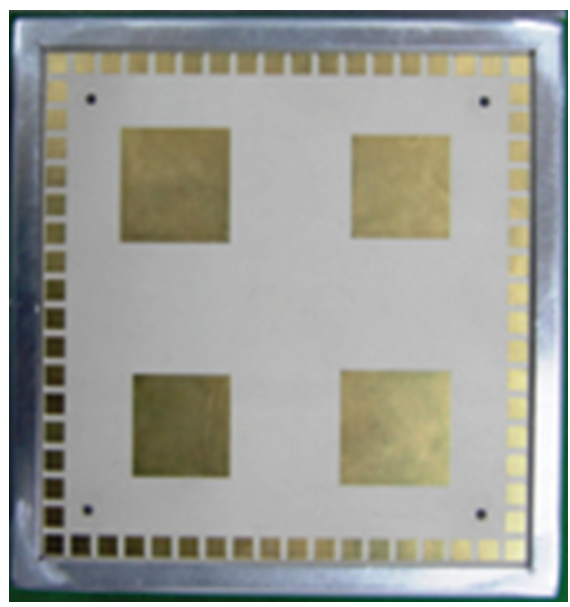

(d) Antenna with housing

FIGURE 9: Photographs of the fabricated two-by-two microstrip patch array antenna.

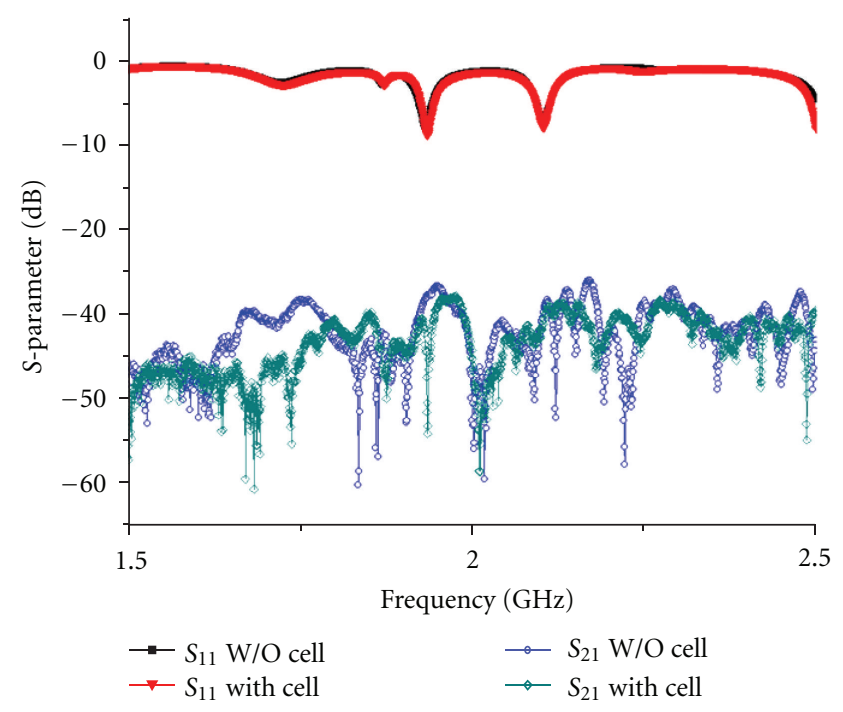

Figure 10: Measured return loss and isolation characteristics of two-by-two microstrip patch array antenna. probe was $100 \Omega$ and the input impedance of each of the patch elements with a proximity coupled microstrip feed is $50 \Omega$. A comparison of the measured return loss $\left(S_{11}\right)$ and isolation $\left(S_{21}\right)$ between a server antenna and a donor antenna with/without isolated soft surface unit cells is shown in Figure 10. It is noted that the resonant frequencies are barely changed.

In the higher and lower bands, the measured $-10 \mathrm{~dB}$ return loss bandwidths are about $84 \mathrm{MHz}$ and $96 \mathrm{MHz}$, respectively. It meets the bandwidth requirement for WCDMA (1.92-2.17 GHz) applications. Compared to the fabricated antenna without isolated soft surface unit cells, the fabricated antenna with isolated soft surface unit cells exhibits higher isolation level. When the isolated soft surface unit cells are used, the maximum isolation level at the frequency of 1.94 and $2.15 \mathrm{GHz}$ is $-92 \mathrm{~dB}$ and $-70 \mathrm{~dB}$, respectively. The measured far-field radiation patterns in the $x$-y plane $\left(\theta=0^{\circ}\right)$ and $y$ - $z$ plane $\left(\phi=0^{\circ}\right)$ at the frequency of 1.94 and $2.15 \mathrm{GHz}$ are shown, respectively, in Figure 11. It shows linear polarized radiation patterns, and the main direction of the radiated power was changed due 


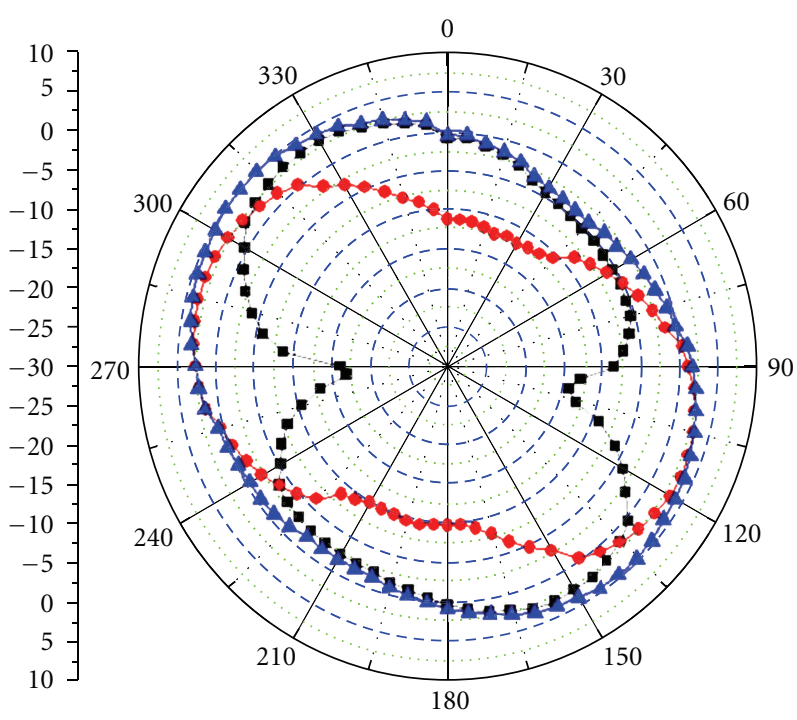

(a) $x-y$ plane $(1.94 \mathrm{GHz})$

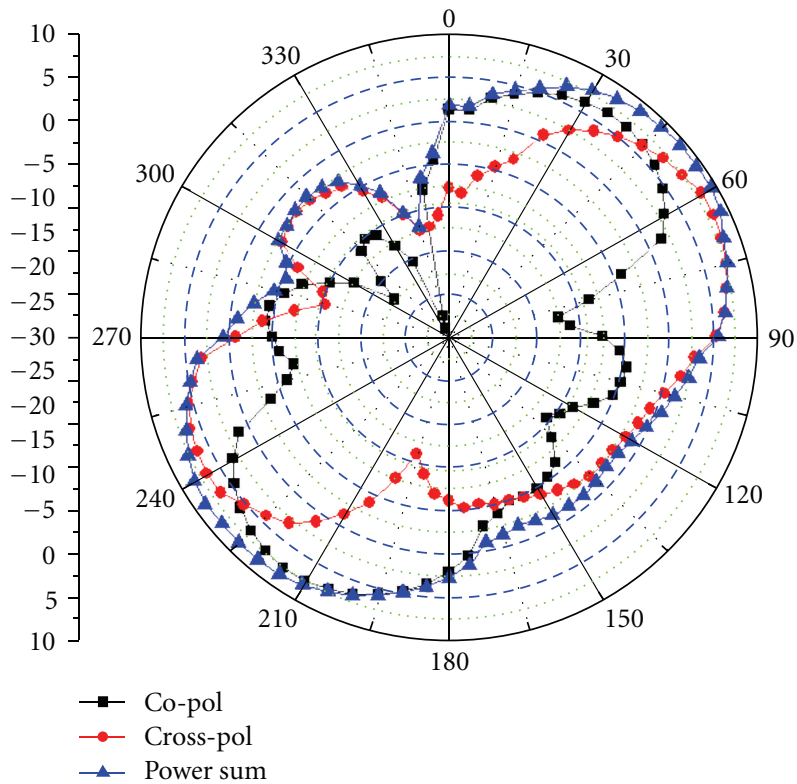

(c) $x-y$ plane $(2.15 \mathrm{GHz})$

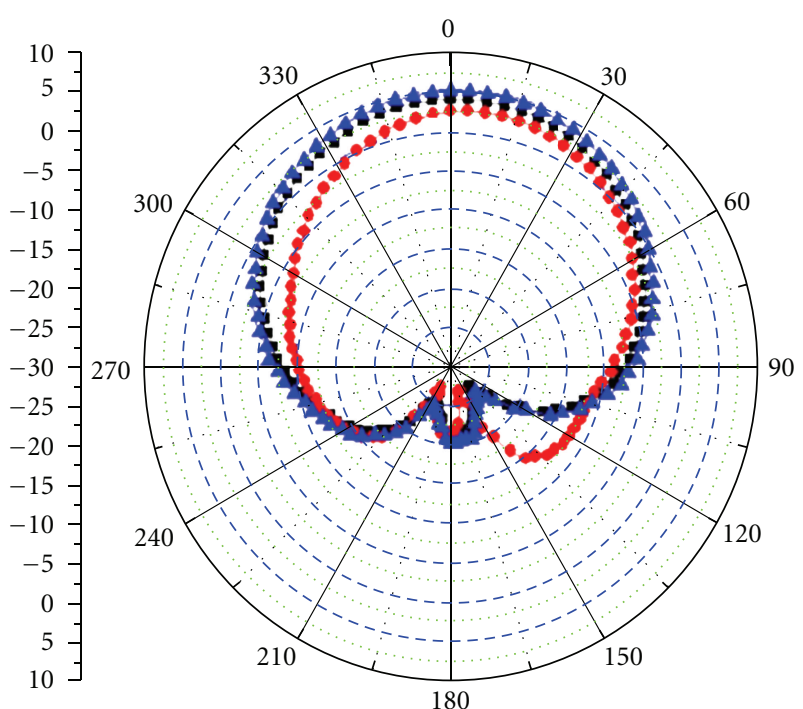

(b) $y$ - $z$ plane $(1.94 \mathrm{GHz})$

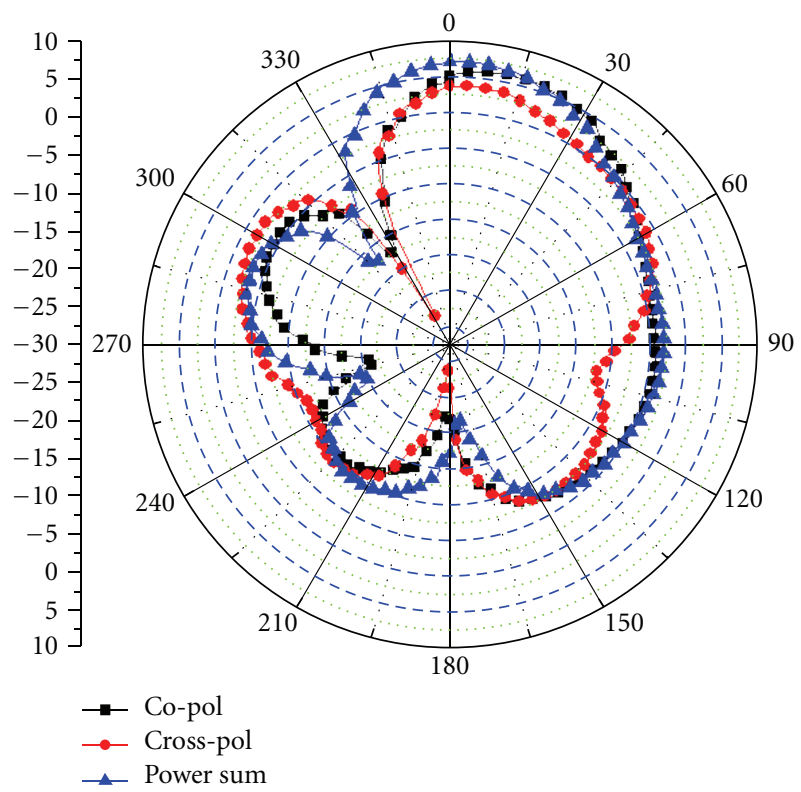

(d) $y-z$ plane $(2.15 \mathrm{GHz})$

FIGURE 11: Measured far-field radiation patterns of the fabricated antenna.

to the placement of two patches. The main beam direction was slanted about $-45^{\circ}$ for the lower band $(\mathrm{Tx})$ and $+45^{\circ}$ for the higher band $(\mathrm{Rx})$. The measured peak gain/radiation efficiency for $\mathrm{Tx} / \mathrm{Rx}$ band was $7.1 \mathrm{dBi} / 77 \%$ and $8.9 \mathrm{dBi} / 80 \%$, respectively.

\section{Conclusion}

The new techniques for the isolation improvement of a microstrip patch array antenna have been presented. The two main techniques presented here are (1) the single-feed switchable feed network structure with MS/NRI coupledline coupler for higher isolation level and (2) the isolated soft surface unit cells structure for reducing the surface waves. Both structures have been discussed in the paper through proper numerical simulation. In order to improve the isolation further, the server antenna and donor antenna for an indoor repeater system were placed orthogonally. As a result, the fabricated server and donor antennas have small separation of $20 \mathrm{~mm}$ and exhibit higher isolation level. Experimental results shows that the maximum isolation level at the frequency of 1.94 and $2.15 \mathrm{GHz}$ is $-92 \mathrm{~dB}$ and $-70 \mathrm{~dB}$, respectively. The proposed techniques can be easily used for 
the design of the microstrip patch array antenna with higher isolation level.

\section{Acknowledgment}

This research was supported by the Basic Science Research Program through the National Research Foundation of Korea (NRF) funded by the Ministry of Education, Science and Technology (no. 2010-0011646).

\section{References}

[1] Y. J. Park, A. Herschlein, and W. Wiesbeck, "A photonic bandgap (PBG) structure for guiding and suppressing surface waves in millimeter-wave antennas," IEEE Transactions on Microwave Theory and Techniques, vol. 49, no. 10, pp. 18541859, 2001.

[2] D. Sievenpiper, L. Zhang, R. F. J. Broas, N. G. Alexöpolous, and E. Yablonovitch, "High-impedance electromagnetic surfaces with a forbidden frequency band," IEEE Transactions on Microwave Theory and Techniques, vol. 47, no. 11, pp. 20592074, 1999.

[3] P. S. Kildal and A. Kishk, "EM modeling of surfaces with stop or go characteristics-artificial magnetic conductors and soft and hard surfaces," Applied Computational Electromagnetics Society Journal, vol. 18, no. 1, pp. 32-40, 2003.

[4] P. S. Kildal, A. A. Kishk, and S. Maci, "Special issue on artificial magnetic conductors, soft/hard surfaces, and other complex surfaces," IEEE Transactions on Antennas and Propagation, vol. 53, no. 1, part 1, pp. 2-7, 2005.

[5] H. M. Lee, "Pattern reconfigurable microstrip patch array antenna using switchable feed-network," in Proceedings of the Asia-Pacific Microwave Conference (APMC'10), pp. 2017-2020, December 2010.

[6] H. M. Lee and J. K. Kim, "Front-to-back ratio improvement of a microstrip patch antenna using an isolated soft surface structure," in Proceedings of the European Microwave Conference (EuMC '09), pp. 385-388, October 2009.

[7] J. H. Kim and H. M. Lee, "Backward wave reduction of a microstrip patch antenna using dual-band isolated soft surface structures," in Proceedings of the IEEE International Symposium on Antennas and Propagation Society (AP-S '10), pp. 1-4, July 2010.

[8] R. Islam and G. V. Eleftheriades, "A planar metamaterial codirectional coupler that couples power backwards," in Proceedings of the IEEE MTT-S International Microwave Symposium Digest, vol. 1, pp. 321-324, June 2003. 

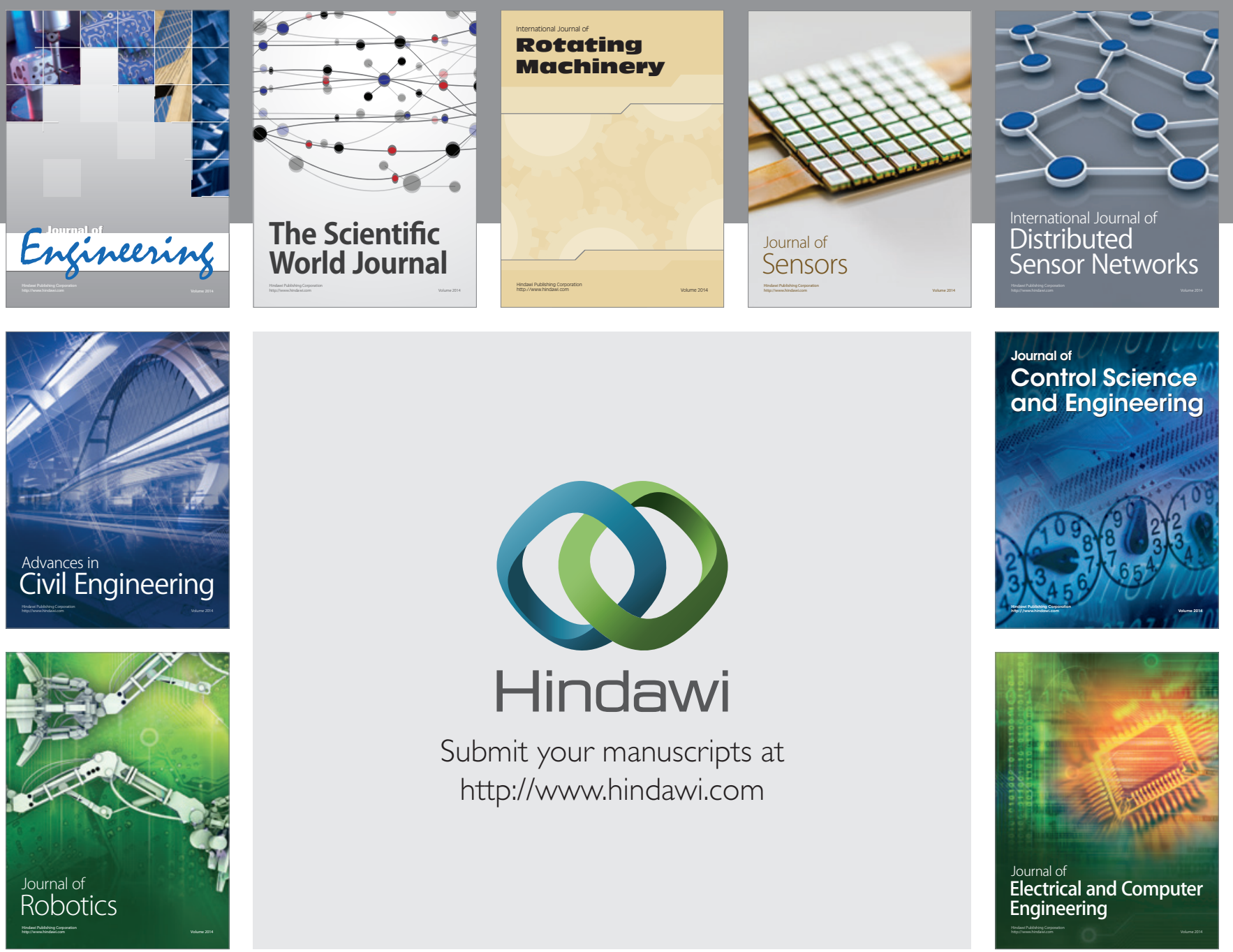

Submit your manuscripts at

http://www.hindawi.com
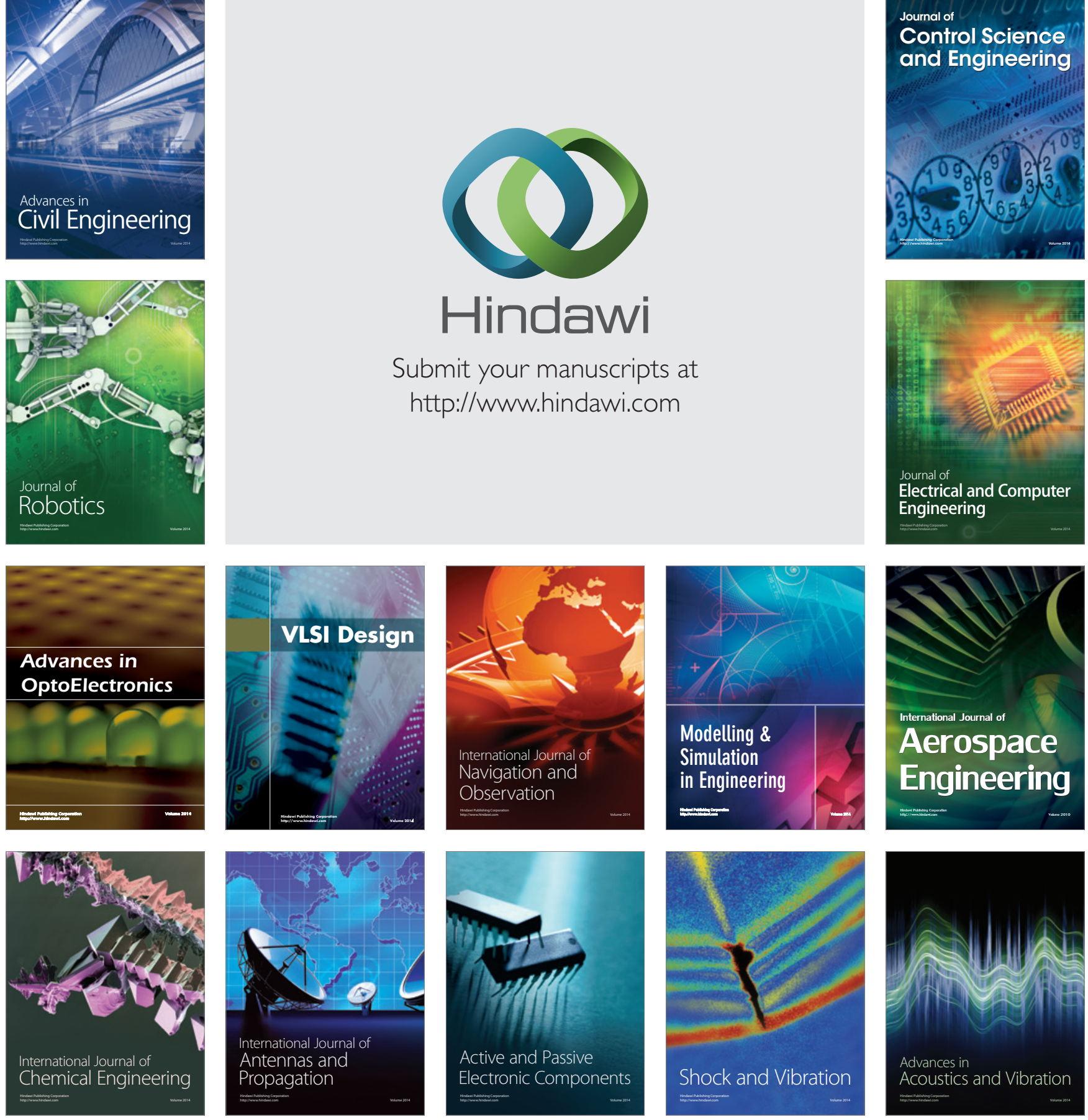